\title{
The anticorrosive performance of zinc-free non-toxic pigment for paints
}

\author{
D. El-Hamid, G. Blustein*, M. Deyá, B. del Amo, R. Romagnoli

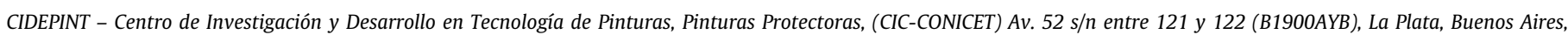 \\ Argentina
}

\section{A R T I C L E I N F O}

\section{Article history:}

Received 9 February 2010

Received in revised form 8 February 2011

Accepted 9 February 2011

\section{Keywords:}

Corrosion

Coatings

Calcium aluminium phosphosilicate

hydrate

Solvent paints

Accelerated tests

\begin{abstract}
A B S T R A C T
The objective of this research was to study the efficiency of calcium aluminium phosphosilicate hydrate (PSh), as anticorrosive pigment for paints in simulated aggressive environments. This compound is zincfree and the phosphate content is less than $30 \%$ by weight. Alkyd and epoxy paints, of the solvent-borne type, containing $30 \%$ by volume ( $\mathrm{v} / \mathrm{v}$ ) of the pigment, were formulated. The pigment volume concentration was fixed at $42.3 \%$. Standardised accelerated salt spray exposure and electrochemical tests were used to assess the protective performance of the coatings. Analysis and interpretation of the experimental data showed that PSh inhibits corrosion of painted steel panels exposed to aggressive environments. Zinc phosphate (ZP), a traditional anticorrosive pigment, was used as reference in all the essays.
\end{abstract}

(c) 2011 Elsevier B.V. All rights reserved.

\section{Introduction}

Organic coatings are commonly used to protect metals against corrosion. They are formulated employing a variety of materials such as pigments, binders, solvents and additives. A suitable combination of these materials may results in a high performance anticorrosive paint able to face the exposition to an aggressive media protecting the substrate below.

Due to environmental regulations the employment of anticorrosive pigments has changed from chromates to phosphates. Zinc phosphate (ZP) has been used as inhibitive pigment for paints during many years. In general, ZP shows good performance in industrial environments due to its ability to passivate steel in acidic media [1,2]. However, discouraging and contradictory results were obtained in rural areas were the $\mathrm{pH}$ of the atmospheric conditions prevent the formation of an effective protective layer $[3,4]$.

Modifications of ZP with molybdenum [5,6] or organic inhibitors $[5,7,8]$ have been reported as suitable strategies to enhance the pigment performance. Furthermore, as the European Community restricted the employment of zinc (directive 76/464 EEC, codified as 2006/11/EEC), modifications of zinc phosphate includes the replacement of the cation by calcium, strontium, aluminium, etc. $[5,9,10]$. More recently, it has been proposed that phosphosilicates could outperform zinc phosphates $[8,11,12]$.

The aim of this work was to study the anticorrosive performance of PSh. The selected pigment was tested by electrochemical

\footnotetext{
* Corresponding author. Tel.: +54 2214831141; fax: +54 2214271537.

E-mail address: pinturashigienicas@cidepint.gov.ar (G. Blustein).
}

techniques (corrosion potential and polarization curves) in water suspension and in solvent-borne coatings. The exposition to the salt spray cabinet, ionic resistance measurements and the electrochemical noise technique were employed to study the protective behaviour of the paints.

\section{Experimental \\ 2.1. Pigments characterisation}

Two anticorrosive pigments were employed to do this research, calcium aluminium phosphosilicate hydrate (PSh) and zinc phosphate (ZP). The density of the pigments, relevant to paint technology was determined according to standardised procedures (ASTM D 1475). pH and conductivity of the aqueous saturated solution were also determined.

\subsection{Evaluation of the inhibitive properties of pigments suspensions}

The inhibitive properties of both pigments were evaluated by electrochemical techniques. The corrosion potential ( $E_{\text {corr }}$ ) of SAE 1010 (UNS G10100) steel electrodes was measured, as a function of time, in the corresponding pigment suspensions. A saturated calomel electrode (SCE) was used as reference and the supporting electrolyte was $0.025 \mathrm{M} \mathrm{NaCl}$. Steel corrosion rate in both pigments suspensions, in $0.1 \mathrm{M}$ $\mathrm{NaCl}$, was also obtained from polarisation resistance measurements employing a conventional three electrode cell. A SCE and a platinum grid were used as reference and counter electrodes, respectively. The swept amplitude was $\pm 20 \mathrm{mV}$ from the open circuit potential and the scan rate was $0.250 \mathrm{mV} \mathrm{s}^{-1}$. Measurements were carried out with a Potentiostat/Galvanostat EG\&G PAR Model 273A plus SOFTCORR 352 software. Anodic and cathodic polarisation curves in a wider potential range were also obtained, employing a similar electrochemical cell.

\subsection{Formulation, elaboration and application of paints}

The resins employed to formulate solvent-borne paints were as follows: a medium oil alkyd (50\% linseed oil, 30\% o-phthalic anhydride, $8 \%$ pentaerythritol and 
Table 1

The composition of solvent-borne paints by volume.

\begin{tabular}{|c|c|c|c|c|c|}
\hline \multirow[t]{2}{*}{ Components } & \multicolumn{5}{|c|}{ Paints } \\
\hline & 1 & $2^{\mathrm{a}}$ & 3 & 4 & 5 \\
\hline Calcium aluminium polyphosphate silicate hydrate (PSh) & 8.9 & 8.9 & 8.9 & - & - \\
\hline Zinc phosphate (ZP) & - & - & - & 8.9 & 8.9 \\
\hline Barium sulphate & 8.2 & 8.2 & 8.2 & 8.2 & 8.2 \\
\hline Talc & 8.2 & 8.2 & 8.2 & 8.2 & 8.2 \\
\hline Titanium dioxide & 3.3 & 3.3 & 3.3 & 3.3 & 3.3 \\
\hline Zinc oxide & 1.0 & 1.0 & 1.0 & 1.0 & 1.0 \\
\hline Epoxy/polyamide resin & 40.4 & 40.4 & - & 40.4 & - \\
\hline Alkyd resin & - & - & 40.4 & & 40.4 \\
\hline Solvent & 30.0 & 30.0 & 30.0 & 30.0 & 30.0 \\
\hline Anticorrosive pigment/total pigment (v/v) & $30 \%$ & $30 \%$ & $30 \%$ & $30 \%$ & $30 \%$ \\
\hline
\end{tabular}

a $2 \%$, by weight, of a wetting agent was added to Paint 2 .

glycerol and $12 \%$ pentaerythritol resinate) and a bisphenol epoxy-polyamide resin $(1: 1$ ratio $\mathrm{v} / \mathrm{v})$. The solvent employed in the former case was white spirit while the mixture xylene/methylisobutylketone/butyl cellosolve (13/45/42\%, by weight, w/w) was used for the epoxy paint. It was decided to check the anticorrosive properties of the pigments employing solvent borne paints because their behaviours have been well documented for many years. The PVC (pigment volume concentration) was, in every case, $42.3 \%$ and the ratio PVC/CPVC (critical pigment volume concentration) was approximately 0.8 .

The anticorrosive pigment load was $30 \% \mathrm{v} / \mathrm{v}$ of the total pigment content; the same pigment content suggested when orthophosphates are employed as anticorrosive pigments $[1,5]$. Barium sulphate, talc, titanium dioxide and a small amount of zinc oxide were incorporated, as complementary pigments, to complete the pigment formula (Table 1). All pigments were dispersed for $24 \mathrm{~h}$ in the vehicle (resin + solvent), employing a ball mill, to achieve an acceptable dispersion degree. Paints formulations are shown in Table 1.

SAE 1010 steel panels $(15.0 \mathrm{~cm} \times 7.5 \mathrm{~cm} \times 0.2 \mathrm{~cm})$ were sandblasted to Sa $21 / 2$ (SIS 055900 ), degreased with toluene and then painted, by brushing, to reach a dry film thickness of $115 \pm 5 \mu \mathrm{m}$. Painted panels were kept indoor for 14 days before testing.

\subsection{Performance of anticorrosive paints in accelerated and electrochemical tests}

A set of three panels was placed in the salt spray chamber (ASTM B-117). Rusting (ASTM D-610) and blistering (ASTM D-714) degrees were evaluated as a function of time up to $1000 \mathrm{~h}$ of exposure.

The resistance between the coated steel substrate and a platinum electrode was measured with an ATI Orion model 170 conductivity meter at $1000 \mathrm{~Hz}$ frequency. The cell to do the measurements was constructed limiting $3 \mathrm{~cm}^{2}$ circular zones on the coated surface by placing an acrylic tube on the specimen and filling it with $0.5 \mathrm{M} \mathrm{NaCl}$.

The cell for electrochemical noise measurements (ENM) was constituted by two nominally identical electrodes and a reference electrode. A low value resistor was placed between the two specimens and current noise was measured as the fluctuation in voltage across the resistor, on the grounds that interference from the electronic circuit will be diminished [13]. The three electrodes were in the same container which made it easier to controll the effect of temperature fluctuations. The edges of the specimens were blanked off leaving $37.8 \mathrm{~cm}^{2}$ of the painted panel exposed to a $0.5 \mathrm{M} \mathrm{NaCl}$ solution. Data were acquired with a NICOLET 310 digital oscilloscope and the corresponding software 310RSWFT. Adequate filtering was provided just to eliminate undesirable signals like line signals [14-16]. The sensitivity of the measuring device in the E-scale was $0.1 \mathrm{mV}$ and $100 \mathrm{nA}$ in current measurements. The sampling frequency was $5 \mathrm{~Hz}$, which is commonly used to study corroding systems [14-16] and data were collected during 800 s. Each set of data was controlled to verify they distribute normally [17]. Statistical analysis of each time series was performed and the noise resistance $\left(R_{\mathrm{n}}\right)$ was calculated as the quotient $R_{\mathrm{n}}=\sigma_{\mathrm{E}} / \sigma_{\mathrm{i}}$ [14-16]. Although the mean values of raw data were plotted, the d.c. trend was removed to perform $R_{\mathrm{n}}$ calculation by the moving average removal procedure described by Tan et al. [18].
The electrochemical noise test was finished when red iron oxide spots were perceived with the unaided eye.

\section{Results and discussion}

\subsection{Pigments characterisation}

The physical and chemical properties of PSh and ZP are summarised in Table 2. As can be seen, the phosphate content was reduced up to $20 \%$ and zinc cation was fully replaced in PSh pigment with respect to traditional ZP. The aqueous extract of none of the pigments has a $\mathrm{pH}$ value alkaline enough as to passivate steel $(\mathrm{pH} \sim 8)$.

\subsection{Evaluation of inhibitive properties of PSh suspension}

$E_{\text {corr }}$ of steel, in contact with PSh suspension, diminished continuously from $-0.320 \mathrm{~V}$ to $-0.410 \mathrm{~V}$ in $4 \mathrm{~h}$ of testing. $\mathrm{ZP}$ had a similar behaviour but at the end of the essay, the corrosion potential was shifted $-0.060 \mathrm{~V}$ with respect to that of PSh (Fig. 1). Steel immersed in the supporting electrolyte exhibited a corrosion potential corresponding to the corroding metal from the beginning of the essay. Afterwards, the potential increased due to the formation of an oxide layer on the surface and finally decrease to a value around $-0.430 \mathrm{~V}$. After 24 h of exposure $E_{\text {corr }}$ of steel in contact with PSh or ZP suspensions was close to $-0.600 \mathrm{~V}$ while the blank has a value of $-0.558 \mathrm{~V}$. In every case, as it could be deduced from the reported values an iron oxides film was formed. However, in the first two cases this film was a grey one while that on the blank was constituted by iron oxides with a reddish colour, typical of corroded steel.

The polarization curves of SAE 1010 steel in the pigments suspension in $0.1 \mathrm{M} \mathrm{NaCl}$ can be seen in Figs. 2 and 3. Steel corrosion rate was calculated from polarisation resistance measurements at two different exposure times. The values obtained for the PSh suspension were $2.39 \mu \mathrm{A} \mathrm{cm}^{-2}$, after $2 \mathrm{~h}$ of immersion and increased to $4.68 \mu \mathrm{Acm}^{-2}$ after $24 \mathrm{~h}$. Steel corrosion rate was higher in ZP suspension: $7.11 \mu \mathrm{A} \mathrm{cm}^{-2}$ and $19.7 \mu \mathrm{A} \mathrm{cm}^{-2}$. The highest values were observed in the blank: $51.7 \mu \mathrm{Acm}^{-2}$ and $104.6 \mu \mathrm{Acm}^{-2}$, after $2 \mathrm{~h}$ and $24 \mathrm{~h}$ of exposure, respectively.

Table 2

Physical and chemical properties of PSh and ZP.

\begin{tabular}{|c|c|c|c|c|c|c|c|c|c|}
\hline \multirow[t]{3}{*}{ Inhibitive pigment } & \multicolumn{7}{|l|}{ Solid } & \multicolumn{2}{|c|}{ Aqueous extract } \\
\hline & \multirow[t]{2}{*}{ Density $\left(\mathrm{g} \mathrm{ml}^{-1}\right)$} & \multicolumn{6}{|c|}{ Composition (\%) } & \multirow[t]{2}{*}{$\mathrm{pH}$} & \multirow{2}{*}{$\begin{array}{l}\text { Conductivity } \\
\left(\mu \mathrm{S} \mathrm{cm}^{-1}\right)^{\mathrm{a}}\end{array}$} \\
\hline & & $\mathrm{H}_{2} \mathrm{O}^{\mathrm{b}}$ & $\mathrm{SiO}_{2}$ & $\mathrm{Al}_{2} \mathrm{O}_{3}$ & $\mathrm{CaO}$ & $\mathrm{ZnO}$ & $\mathrm{P}_{2} \mathrm{O}_{5}$ & & \\
\hline PSh & 2.6 & 8.0 & 28.0 & 7.0 & 31.0 & - & 26.0 & 7.1 & 86.0 \\
\hline ZP & 3.3 & 8.5 & - & - & - & 57.9 & 33.6 & 6.5 & 50.8 \\
\hline
\end{tabular}

a Conductivity of $0.1 \mathrm{M} \mathrm{KCl}$ is $14 \mathrm{mS} \mathrm{cm}^{-1}$.

b Loss at $600^{\circ} \mathrm{C}$. 


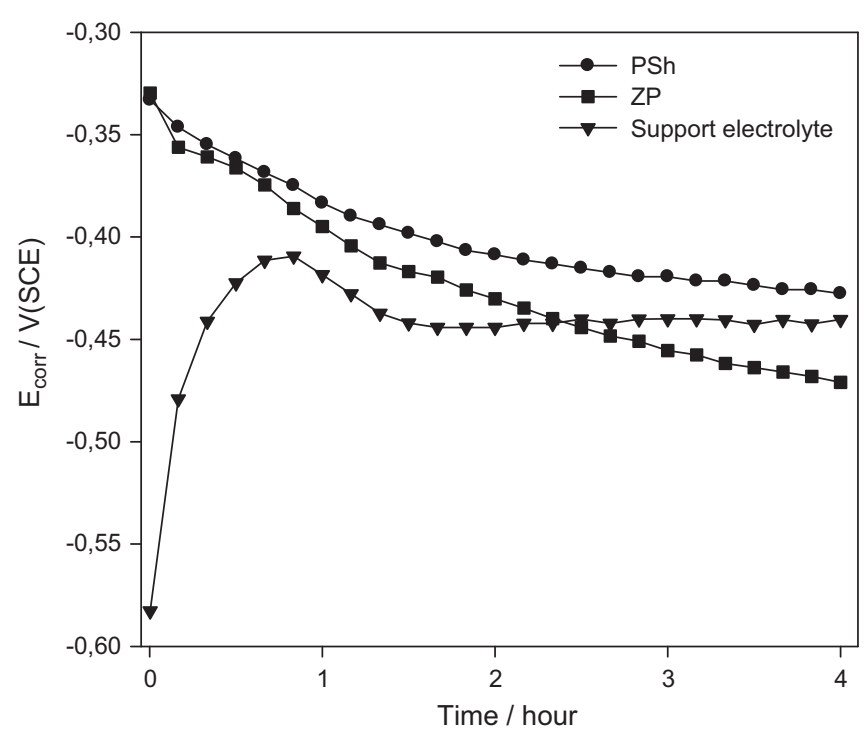

Fig. 1. Corrosion potential of steel immersed in pigment suspension.

The anodic curve of steel immersed in PSh suspension was sensibly lower than in the presence of support electrolyte after $2 \mathrm{~h}$ of immersion and at lower overpotentials. At higher overpotentials, the dissolution reaction is less polarized than in the case of steel immersed in support electrolyte. After $24 \mathrm{~h}$ the anodic reaction is much more polarized in the presence of PSh in the whole potentials interval. In the presence of ZP certain passivity was originated on steel substrate, probably, by the phosphate anion; however, as the electrolyte has chloride anion the region could not be well defined. The curve of steel immersed in ZP showed that the better inhibition occurs after $2 \mathrm{~h}$ of exposition due the current was sensibly lower than the one obtained of steel immersed in the support electrolyte. This situation was repeated after $24 \mathrm{~h}$ of immersion despite the corrosion currents were higher. At high overpotentials, the dissolution of steel is highly polarized in the presence of ZP.

The cathodic current in presence of PSh was $15 \mu \mathrm{A} \mathrm{cm}^{-2}$ and it did not change significantly after $24 \mathrm{~h}$, this showed that the cathodic reaction of oxygen as well as the anodic reaction is inhibited. In the case of $\mathrm{ZP}$, the cathodic current increased from $12 \mu \mathrm{Acm}^{-2}$ up to $300 \mu \mathrm{Acm}^{-2}$. This last value is higher than the oxygen reduction current on a platinum electrode in the same electrolyte, $\sim 220 \mu \mathrm{A} \mathrm{cm}^{-2}$. This showed that, besides oxygen, corrosion prod-

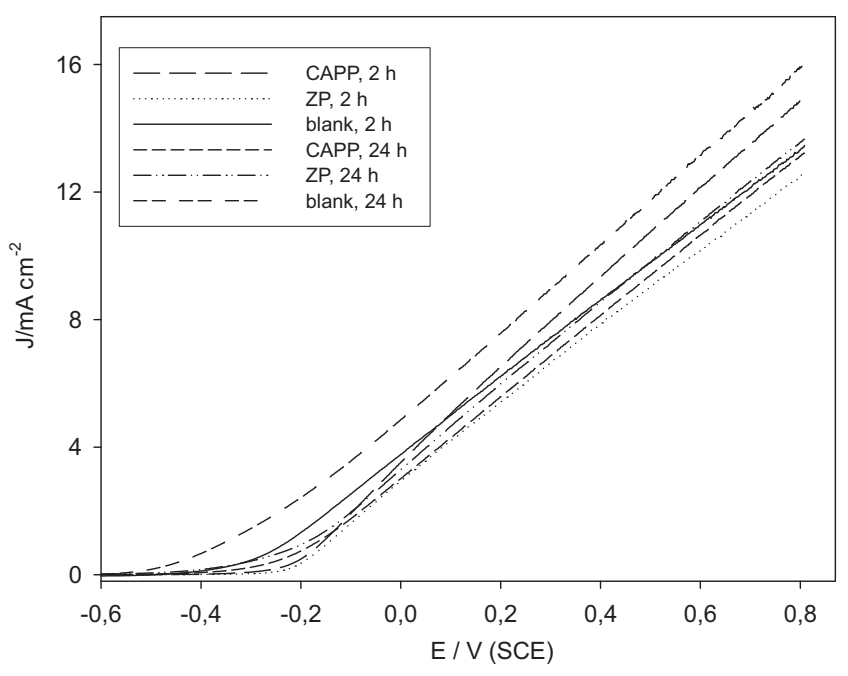

Fig. 2. Anodic polarization curves of steel immersed in the pigments suspension.

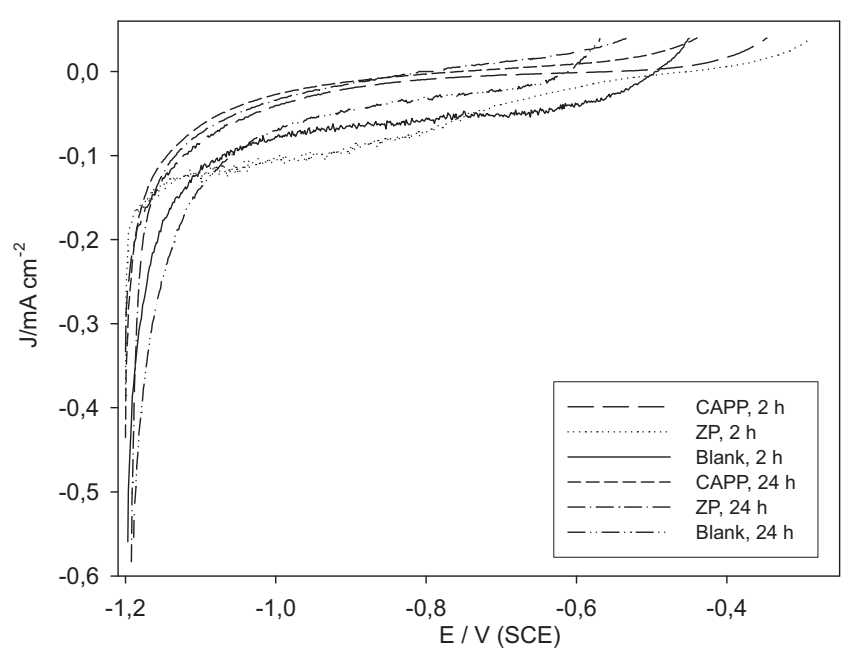

Fig. 3. Cathodic polarization curves of steel immersed in the pigments suspension.

ucts may be reducing as well. The current observed when the support electrolyte was employed diminished after $24 \mathrm{~h}$, probably due to the accumulation of corrosion products, to values around $30 \mu \mathrm{A} \mathrm{cm}^{-2}$.

The potential values at zero current, corrosion potentials, were more negatives than the ones shown in Fig. 1 due to the higher concentration of chloride anions employed in the polarization tests. After $24 \mathrm{~h}$ of immersion the systems that contained phosphates were more active as the corrosion potential shifted to more negative values, despite that the corrosion rate did not increase significantly. This could be due to an increase in the thickness of the protective oxide layer that is normally present on the electrode in presence of phosphates.

Briefly, steel corrosion rate was significantly lowered in the presence of PSh even in comparison with zinc phosphate.

\subsection{Performance of anticorrosive paints in accelerated tests}

The performance of PSh in the salt spray chamber depends on the resin employed to formulate the paint. Epoxy paint presented a poor protective behaviour (Paint 1). This behaviour was improved by adding a wetting additive in such a way that better qualification was obtained after $912 \mathrm{~h}$ of exposition (Paint 2). Panels coated with the alkyd paint containing PSh were qualified after $576 \mathrm{~h}$, offering an acceptable protection to steel up to $1000 \mathrm{~h}$ of testing. This is particularly interesting if one takes into account that the alkyd resin has a regular resistance to water and chemical compounds. This type of resin wetted solid particles quite easily forming a homogenous dispersion of solid particles.

Paints formulated with ZP had very good performance, despite the resin employed in the formulation; they last for $1000 \mathrm{~h}$ without rust dots or blisters.

Comparing the pigments performance, it must be concluded that the protective ability of PSh is lower than that of ZP. However, alkyd or epoxy-additive paint pigmented with PSh had a satisfactory behaviour. These results agree with the ones obtained by Vesely and Jaskova [8] in water-borne paints employing different phosphosilicates and zinc orthophosphate as active pigments. The authors attributed the lower anticorrosive performance of tested phosphosilicates to the lack of zinc in the molecule.

\subsection{Performance of anticorrosive paints in electrochemical tests}

The ionic resistance (Fig. 4) of the painted panels was measured during 26 days. Only paint 5 showed a good barrier protection 


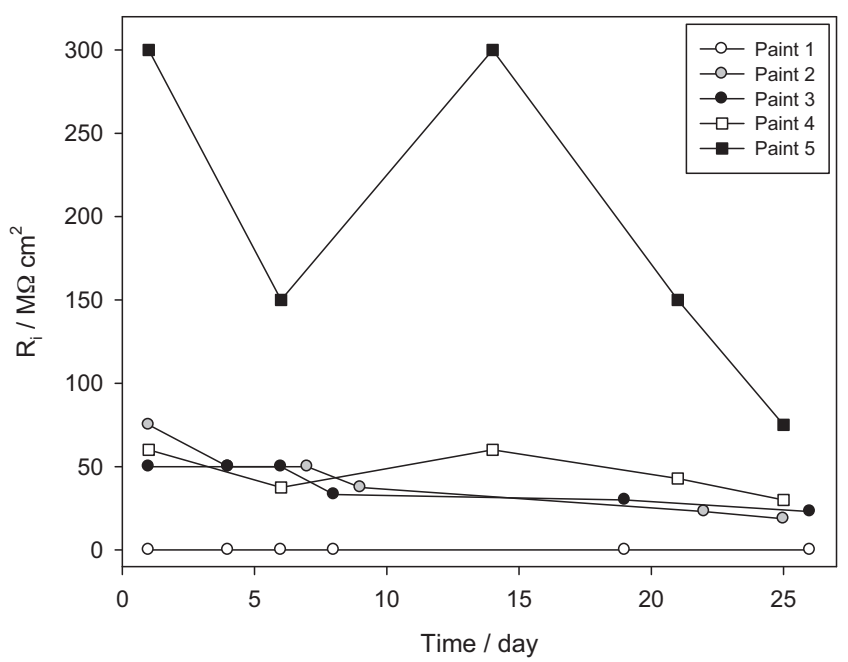

Fig. 4. Ionic resistance of painted steel.

effect, as the ionic resistance was higher than $100 \mathrm{M} \Omega \mathrm{cm}^{2}$. The ionic resistance of paint 1 was the lowest one. It was below $0.02 \mathrm{M} \Omega \mathrm{cm}^{2}$ at the beginning of the test and diminished continuously to reach $1.8 \mathrm{k} \Omega \mathrm{cm}^{2}$ after 26 days of immersion. The other paints have resistance values higher than $2 \mathrm{M} \Omega \mathrm{cm}^{2}$ indicating that there was a certain barrier protection. As the epoxy paint normally possesses certain barrier effect $\left(R_{\mathrm{i}}>1 \mathrm{M} \Omega \mathrm{cm}^{2}\right)$ it was supposed that there existed certain incompatibility between the binder and the pigment as a consequence of its silica fractions. This incompatibility diminished when a wetting agent was added because the ionic resistance increased.

From data in Figs. 5 and 6, it could be seen that PSh performed better with alkyd paints while ZP seemed to be more suitable for epoxies. The behaviour of the alkyd paint pigmented with PSh was satisfactory beyond 3 weeks of immersion. The mean coupling current (Fig. 6) was low during 3 weeks and, finally, increased indicating the onset of corrosion. In change, the coupling current of the alkyd paint formulated with ZP increased to very high values and then, decreased due to surface coverage with iron oxides. The epoxy paint containing PSh (Paint 1 ) failed after 20 days of immersion. High coupling currents (Fig. 6) were measured and the noise potential moved quickly to negative values corresponding to painting steel undergoing corrosion (Fig. 5). As it was said previously,

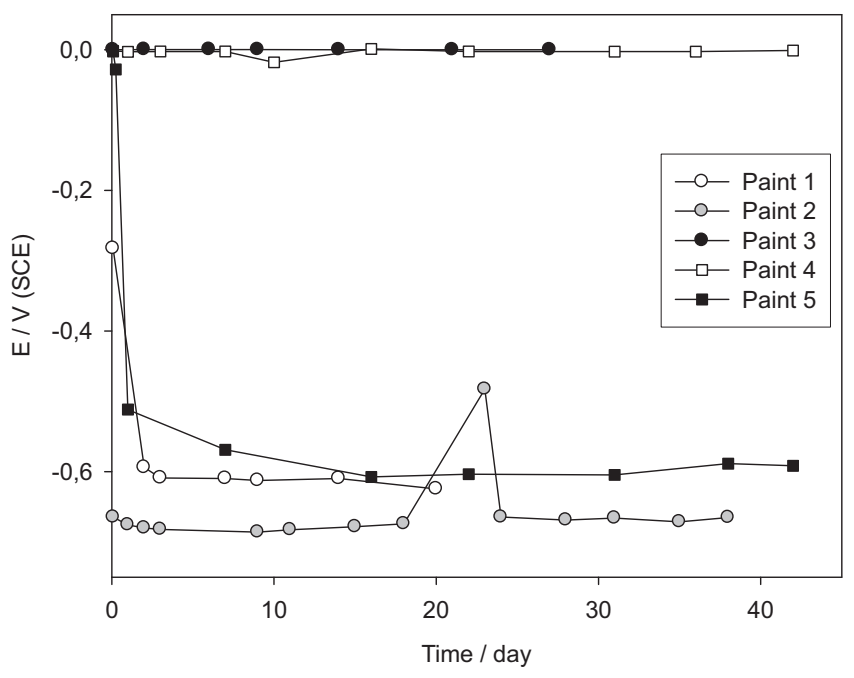

Fig. 5. Mean noise potential of painted steel.

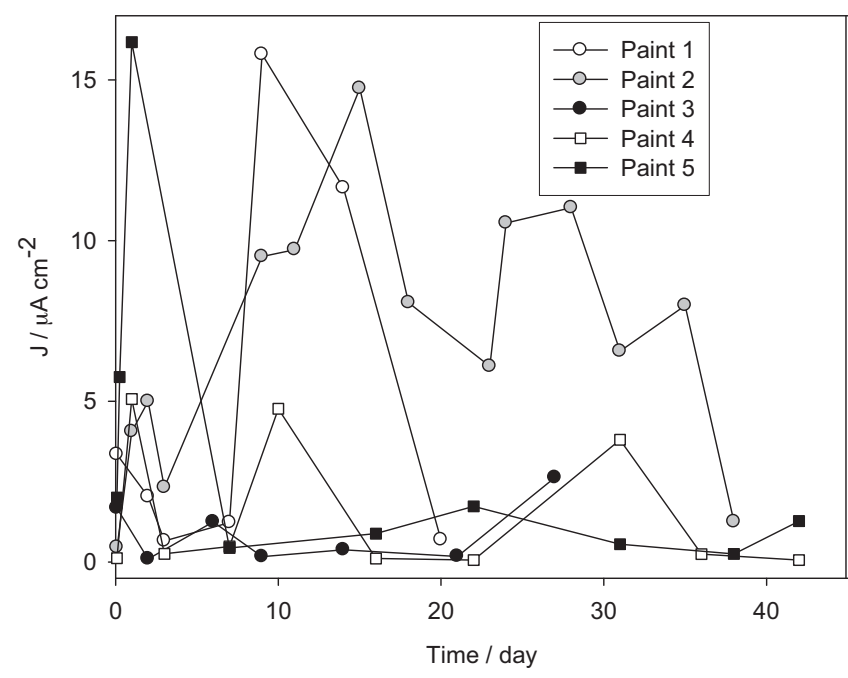

Fig. 6. Mean coupling current of painted steel.

their behaviour was attributed to the fact that pigment particles were not wetted by the binder. So, ionic resistance decreased and the system became prone to corrosion. When a suitable additive was incorporated to the formulation, the protection was extended till 77 days of immersion. However, the negative values of the noise potential observed during the whole test period suggested that an iron oxide layer, may be protective, was grown under the paint film. The coupling current oscillations pointed out some degree of protection of the steel substrate. Finally, the coupling current decreased due to the formation of the protective layer.

The epoxy paint with ZP showed noise potential close to $0 \mathrm{~V}$ thus indicating full protection of the steel substrate during the test. The coupling current of the epoxy paint with ZP was lower than that of the epoxy with PSh and diminished at the end of the exposure period. Table 3

The noise resistance, Fig. 7, was too low and could not be compared with the polarization resistance because the corrosion process is under ohmic control due to the high ionic resistance of the coating [19-21]. In this particular case, the similarity between $R_{\mathrm{n}}$ and the polarization resistance did not hold any longer, as it was stated by several researchers [22,23]. It is beyond the aim of this paper to assign a physical meaning to $R_{\mathrm{n}}$ because more information about the electrochemistry of the system would be required.

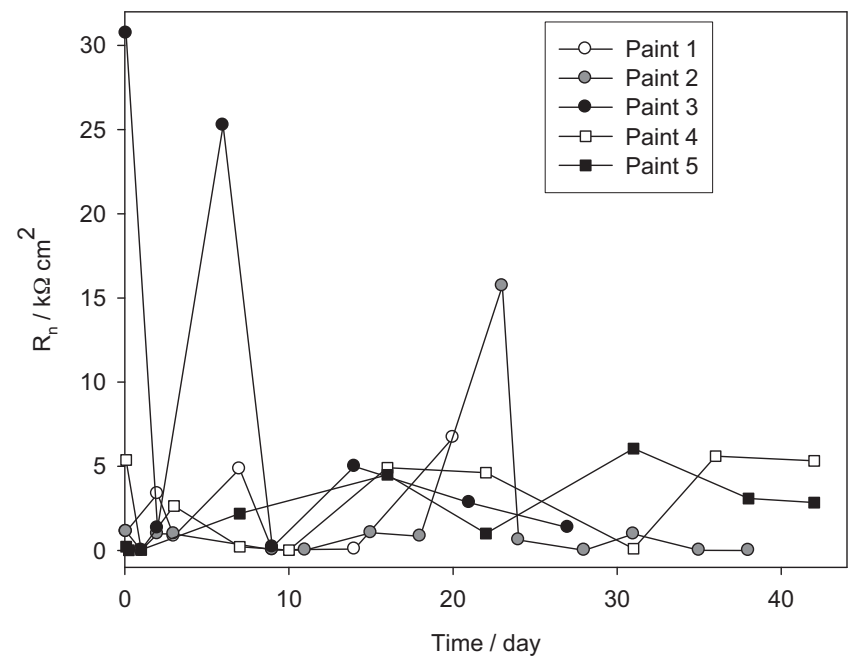

Fig. 7. Noise resistance of painted steel. 
Table 3

Rusting and blistering degrees of painted panels after the salt spray test.

\begin{tabular}{|c|c|c|c|c|c|c|c|c|c|c|}
\hline \multirow[t]{3}{*}{ Hours of exposure } & \multicolumn{10}{|l|}{ Paints } \\
\hline & \multicolumn{2}{|l|}{1} & \multicolumn{2}{|l|}{2} & \multicolumn{2}{|l|}{3} & \multicolumn{2}{|l|}{4} & \multicolumn{2}{|l|}{5} \\
\hline & $\overline{R^{\mathrm{a}}}$ & $\overline{B^{\mathrm{b}}}$ & $R^{\mathrm{a}}$ & $B^{\mathrm{b}}$ & $R^{\mathrm{a}}$ & $B^{\mathrm{b}}$ & $\overline{R^{\mathrm{a}}}$ & $B^{\mathrm{b}}$ & $R^{\mathrm{a}}$ & $B^{\mathrm{b}}$ \\
\hline 96 & 9 & 10 & 10 & 10 & 10 & 10 & 10 & 10 & 10 & 10 \\
\hline 192 & 9 & 10 & 10 & 10 & 10 & 10 & 10 & 10 & 10 & 10 \\
\hline 360 & 8 & 10 & 10 & 10 & 10 & 10 & 10 & 10 & 10 & 10 \\
\hline 576 & 6 & $8 \mathrm{~F}$ & 10 & 10 & 9 & 10 & 10 & 10 & 10 & 10 \\
\hline 720 & - & - & 10 & 10 & 9 & 10 & 10 & 10 & 10 & 10 \\
\hline 912 & - & - & 9 & 10 & 9 & $1 \mathrm{~F}$ & 10 & 10 & 10 & 10 \\
\hline 1000 & - & - & 9 & 10 & 9 & $1 \mathrm{~F}$ & 10 & 10 & 10 & 10 \\
\hline \multicolumn{11}{|c|}{ a Rust grade according ASTM D 610} \\
\hline Rust Grade & 10 & 9 & 8 & 7 & 6 & 5 & 4 & 3 & 2 & 1 \\
\hline Rusted area/\% & No rusted & 0.03 & 0.1 & 0.3 & 1 & 3 & 10 & 16 & 33 & 50 \\
\hline \multicolumn{11}{|c|}{ bBlistering degree according ASTM D 714} \\
\hline Frequency & \multicolumn{2}{|l|}{ Dense (D) } & \multicolumn{4}{|c|}{ Medium dense (MD) } & \multicolumn{3}{|c|}{ Medium (M) } & Few $(F)$ \\
\hline Size & \multicolumn{2}{|l|}{10} & \multicolumn{4}{|l|}{8} & \multicolumn{2}{|l|}{6,4} & & 2 \\
\hline Comments & \multicolumn{2}{|l|}{ No blistering } & \multicolumn{4}{|c|}{ Smaller size blister easily seen by unaided eye } & \multicolumn{4}{|c|}{ Progressively larger sizes } \\
\hline
\end{tabular}

\section{Conclusions}

Alkyd paint with calcium aluminium phosphosilicate hydrate and epoxy paint of this same pigment, with a wetting agent, protected steel in an acceptable way, despite the very low zinc content in the paints formula. Taking into account the restrictions nowadays exits to the disposal of zinc, calcium aluminium phosphosilicate could be a suitable replacement for zinc phosphate in aggressive media.

\section{Acknowledgements}

The authors are grateful to CONICET (Consejo Nacional de Investigaciones Científicas y Técnicas), UNLP (Universidad Nacional de La Plata) and Comisión de Investigaciones Científicas de la Provincia de Buenos Aires (CIC) for their sponsorship to do this research. The authors also thank to Raúl Pérez for the analytical determinations and to POLIDUR S. A. for providing the alkyd resin to carry out this research.

\section{References}

[1] R. Romagnoli, V.F. Vetere, Corros. Rev. 13 (1995) 45.
[2] P. Sorensen, S. Kiil, K. Dam-Johansen, C. Weinell, J. Coat. Technol. Res. 6 (2009) 135.

[3] J. Burkill, J. Mayne, J. Oil Colour Chem. Assoc. 9 (1988) 273.

[4] A. Amirudin, C. Barreau, R. Hellouin, D. Thierry, Progr. Org. Coat. 25 (1995) 339.

[5] G. Adrian, A. Bittner, J. Coat. Technol. 58 (1986) 59.

[6] M. Bethencourt, F. Botana, M. Marcos, R. Osuna, J. Sánchez-Amaya, Progr. Org. Coat. 46 (2003) 280.

[7] A. Kalendova, D. Vesely, J. Stejskal, Progr. Org. Coat. 62 (2008) 105.

[8] D. Vesely, V. Jasková, Transfer Inovácii 15 (2009) 151.

[9] G. Adrian, A. Bittner, M. Gawol, European supplement to Polym, Paint Colour J. 14 (1981) 62.

[10] M. Hernández, J. Genescá, J. Uruchurtu, F. Galiano, D. Landolt, Progr. Org. Coat. 56 (2006) 199.

[11] T. Schauer, W. Liu, L. Dulog, Eur. Coat. J. 3 (1997) 233.

[12] L. Raskovic, D. Djorddjevic, S. Cakic, Working Living Environ. Prot. 2 (1997) 1.

[13] P.R. Roberge, R. Beaudoin, V.S. Sastri, Corros. Sci. 29 (1989) 1231.

[14] J.R. Kearns, J.R. Scully, P.R. Roberge, D.L. Reichert, J.L. Dawson(Eds.), ASTM, 1277, STP, USA, 1996.

[15] R.A. Cottis, Corros. NACE 57 (2001) 265.

[16] F. Huet, Electrochemical Noise Technique, in: P. Marcus, F. Mansfeld (Eds.), Analytical Methods in Corrosion Science and Engineering, CRC Taylor \& Francis, USA, 2005.

[17] S. Mabbutt, D.J. Mills, C.P. Woodcock, Progr. Org. Coat. 59 (2007) 192.

[18] Y.J. Tan, S. Bailey, B. Kinsella, Corros. Sci. 38 (1996) 1681.

[19] J. Yong-Jun Tan, Corros. Sci. Eng. 1 (2007) 1.

[20] J.F. Chen, W.F. Bogaerts, Corros. Sci. 37 (1995) 1839.

[21] A.M. Lowe, H. Eren, S.I. Bailey, Corros. Sci. 45 (2003) 941

[22] J.B. Lumsdem, M.W. Kendig, S. Jeanjaquet, Corros. NACE 224 (1992) 1.

[23] F. Mansfeld, H. Xiao, J. Electrochem. Soc. 140 (1993) 2205. 